\title{
Analysis of the influence of the barrier against a range of active and passive RFID and its performance
}

\author{
Mochammad Junus ${ }^{1}$, Tundung Subali Patma ${ }^{1}$, Awan Setiawan ${ }^{1}$, Arddy Awangga Kusuma ${ }^{1}$, and Isa Mahfudi ${ }^{1}$ \\ ${ }^{1}$ State Polytechnic of Malang, Department of Electrical Engineering, Jl. Soekarno-Hatta No. 9, Malang 65141, Indonesia
}

\begin{abstract}
RFID is classified into 2 based on its power supply i.e. passive RFID and active RFID. The purpose of this research is to know the influence of the media barrier in the form of iron, aluminium, marble, glass, wood, and acrylic, to prove the influence of position of laying on tags that tilted and upright against a range of active RFID readout and passive. Knowing the shape of the radiation pattern between active and passive RFID. The most media give influence on the range of active RFID is aluminium which resulted 2.38 and the lowest media gives influence on the range of active RFID is wood which resulted $10.21 \mathrm{~m}$. Whereas in passive RFID, the most media give influence on the range of passive RFID is Aluminium which resulted $0 \mathrm{~cm}$ and the lowest media give influence on the range of passive RFID is acrylic which resulted $42.7 \mathrm{~cm}$. in testing about the influence of laying on the position of the tags obtained that in Active RFID or RFID passive can be inferred that the laying position tags give influence on the range of readings on the position of the direction of $\mathrm{Y},-\mathrm{Y}, \mathrm{X}$. X.
\end{abstract}

\section{Introduction}

A wide range of identification technology has been present and provide convenience for its users in terms of doing activities identifies an object. This identification technology, among others, barcode, OCR (Optical Character recognition), fingerprint and RFID. The presence of a variety of these technologies allows the speed, security and accuracy in the process of identifying. Among the four identification technology, there is technology that is at the moment so popular is used and developed for a wide range of fields, in regard the process of identifying the advantages i.e. RFID. RFID (Radio Frequency Identification) is the process of identification of a person or object by using the frequency of radio transmission [1]. RFID uses radio frequencies to read information from a small device called a tag. Tag is affixed to a media object. Tags can bring unique information, such as: serial number, model, color, place of Assembly, and other data from the object [1]. RFID has the advantage over the barcode technology i.e. has a range of further, identifying the reading/identification quicker and not have to check one by one and this RFID technology has been widely implemented in a variety of fields [1] [2].

RFID is classified into 2 based on its power supply i.e. passive RFID and active RFID [2]. The difference of the two is on active RFID tag has his own power so it does not need the power of the reader, whereas in the RFID passive tag to work, require power from the reader via the electromagnetic fields from a reader [3].

The fundamental difference between active and passive RFID. RFID is in the range of reading his tags.
Active RFID range reading tag further than passive RFID. The range of reading RFID reader with tags have a wide range of parameters. RFID reading capability against tags is affected by two kinds of things IE technology factors and environmental factors. Technological factors include the type of tag, tag size, laying on the tag, the tag angle, orientation, weight, range, laying on the antenna angle reader, reader, power levels, levels range tag-reader and interference while environmental factors include temperature, humidity, distractions, electrical fields and magnetic fields.

A variety of kinds of parameters and characteristics of RFID on this research intends to know the performance of the RFID specifications 2 i.e. passive RFID and active RFID.

\subsection{Radio Frequency Identification (RFID)}

RFID is one of the few group identification technology automatic like barcode, OCR, magnetic ink, voice recognition, touch memory, smart cards, biometrics [3]. RFID technology is a tool for collecting data about a particular item without the need to touch or look at the data, through the use of inductive coupling or electromagnetic waves. Data carrier is a microchip that is attached to an antenna that is generally called a transponder or tag. Tag is able to transmit information to the reader (transceiver) in a certain range can forward the information to the host computer.

The main components of RFID consists of tags and RFID reader. The tag is the actual data devices carry RFID system, usually composed of elements of the clutch and electronic microchips. The tag is located on

* Corresponding author: mochammad.junus@polinema.ac.id 
the object will be identified while the layout of the reader depends on the design and technology used. Reader in General contains radio frequency module (transmitter and receiver). Sometimes the Reader uses an additional interface (RS 232, RS 485 etc.) that allows to forward the received data to other systems such as PC, control systems and robots [4]. The main components of RFID shown in Figure 1.

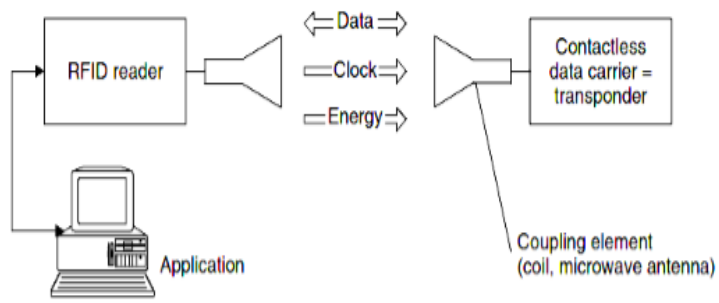

Fig. 1. The Main Components of RFID [4].

\subsection{Classification of RFID}

RFID can be classified on the basis of power i.e. passive RFID and active RFID.

\subsubsection{Passive RFID}

Passive tags are generally always use the antenna and chip. Chip takes power from the RF signal transmitted by the RFID Reader. Tags transmit data back through his switcher input impedance between the two on the spot and modulate the signal backscattered. In each place the impedance RFID tags serves part of the radar cross section (RCS). One place is usually high impedance (high) and the other is low (low) to provide a significant difference in backscattering signals from tags [5]. Passive RFID system is shown in Figure 2.

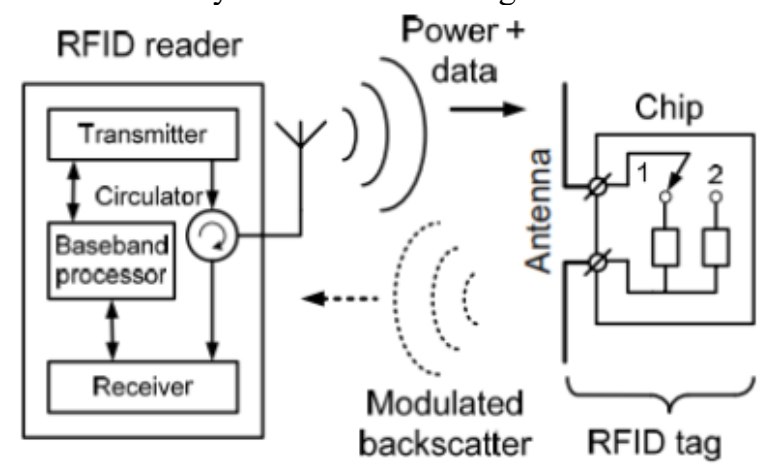

Fig. 2. Passive RFID System [5].

\subsubsection{Active RFID}

RFID active generally there is a battery on the tag, so there is no need to provide induction flow requirements are not as with passive RFID. On active RFID tags designed specifically to use electronic devices including microprocessors and various types of sensor or device i/o. active RFID tags should ideally on the environment with electromagnetic interference due to active RFID tags can broadcast a stronger signal in situations which require a greater distance between the tag and Reader.

Active RFID reader emits radio waves in the range anywhere from an inch to 100 feet or more, depending on its power output and the radio frequency being used. Antennas emit radio signals to enable tag and read and write data to it. When an RFID tag passes through the electromagnetic zone, it detects the activation signal readers. Reader decoded the data encoded in the tag integrated circuit (silicon chip) and the data will be forwarded to the computer to be processed [2]. How RFID work shown in Figure 3.

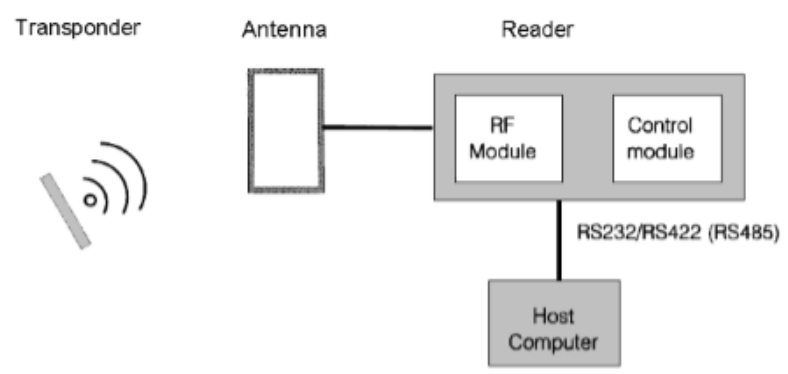

Fig. 3. The workings of RFID [2].

\subsection{The frequency}

RFID tags are basically uses two types of data transmission, depending on the behavior of electromagnetic fields at frequencies used. In the lower frequencies (such as $125-134 \mathrm{kHz}$ band in LF or HF at $13 \mathrm{MHz}$ in the band) using inductive coupling. While the above frequency (UHF frequency range with a typical $433 \mathrm{MHz}, 865-956 \mathrm{MHz}$ and $2.45 \mathrm{GHz}$ ), used as the primary means of backscattering wave transmission between the tag with the RFID reader [3].

\subsection{Interface}

RFID interface can be classified into 2 i.e. RS232 and Weagand 26. RS-232 interface is the Electronic Industries Association (EIA) standard for the exchange of binary data series between two devices. This standard allows the signal to be defined as many as 20 , but gives full freedom to the user. Three wires are enough: transmit data, receive data, and signal ground. The remaining lines can be embedded permanently on or off. Bipolar signal transmission, need two voltage, from 5 to 25 volts, the opposite polarity [6]. RS232 signal form shown Figure 4.

Wiegand card is the most popular identification of the years 1980-90s namely magnetic card with Wiegand wires are embedded in the plastic. Reader use "interface Wiegand" which became the de facto industry standard for interfacing card readers (Reader). Data formats Wiegand is characterized by the total number of bits and the distribution of the field data on the card. Wiegand format consists of a parity bit, 8-bit code facilities, 16-bit user ID, and the parity bit, for a total of $26(1+8+16+$ $1=26$ ) bits [7]. 26 bit wiegand format shown in Figure 5. 


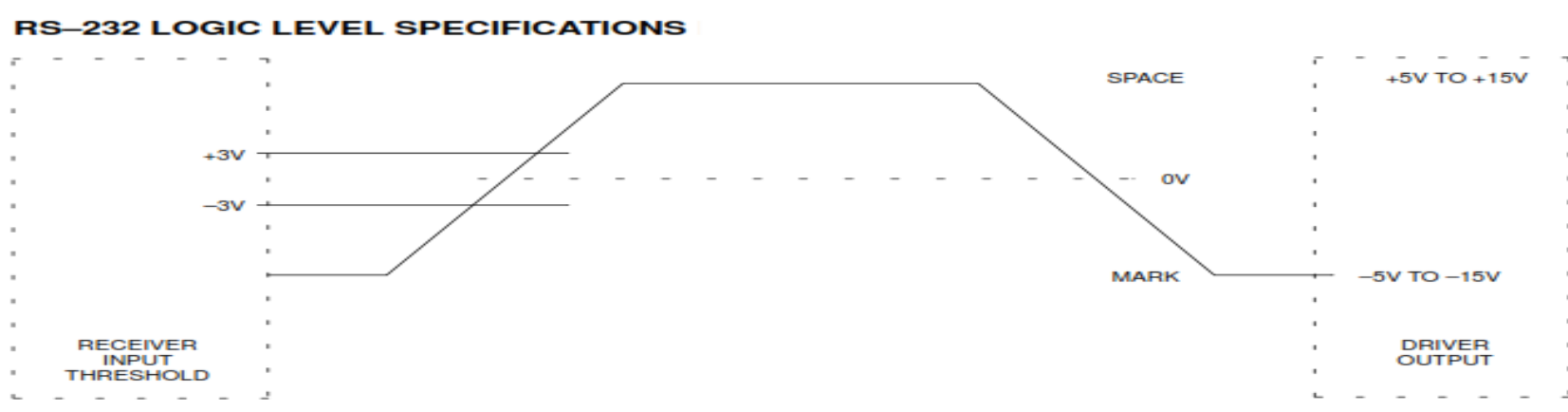

Fig. 4. The Shape of the Signal RS232 [6].

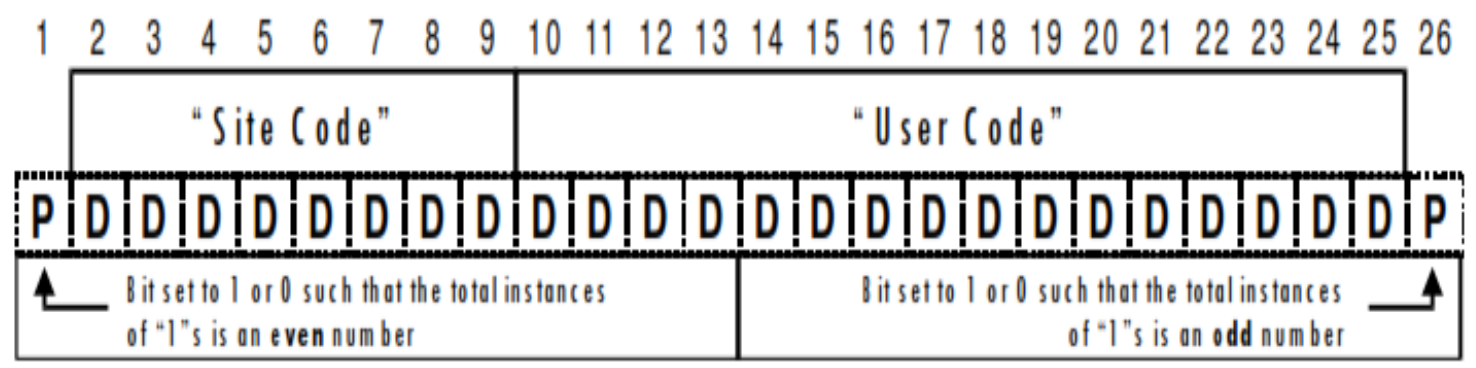

Fig. 5. 26 bit wiegand format [7].

\section{Method}

This testing is done on RFID passive and active RFID. For passive RFID being used is "Long Range RFID Proximity Wiegand" and Active RFID used is "RFID pegasus seri PF5210". Method of testing done on this research consists of:

\subsection{The influence of the barrier}

This test is done to find out the impact of each barrier against media coverage of reading RFID Reader. Test about influence of obstructions done by two methods, namely:

\subsubsection{Blocking tag}

Blocking Tag using the barrier with the thickness indicated in Table 1 while regarding the size dimensions of the barrier are shown on Table 2.

Table 1. The thickness of each barrier materials used.

\begin{tabular}{|c|c|c|}
\hline No & Material Barrier & Thickness (mm) \\
\hline 1 & Iron & 0,5 \\
\hline 2 & Marble & 6 \\
\hline 3 & Acrylic & 2 \\
\hline 4 & Wood & 2 \\
\hline 5 & Glass & 5 \\
\hline 6 & Aluminium & 0,5 \\
\hline
\end{tabular}

\footnotetext{
* Corresponding author: mochammad.junus@polinema.ac.id
}

Table 2. The dimensions of the media barrier used to block tags.

\begin{tabular}{|c|c|l|}
\hline No & Material Barrier & $\begin{array}{c}\text { The Dimensions Of } \\
\text { The Media Barrier }\end{array}$ \\
\hline 1 & Iron & $\begin{array}{l}\text { The length }: 13,4 \mathrm{~cm} \\
\text { The width }: 13,6 \mathrm{~cm}\end{array}$ \\
\hline 2 & Marble & $\begin{array}{l}\text { The length }: 13,4 \mathrm{~cm} \\
\text { The width }: 13 \mathrm{~cm}\end{array}$ \\
\hline 3 & Acrylic & $\begin{array}{l}\text { The length }: 15,9 \mathrm{~cm} \\
\text { The width }: 13,3 \mathrm{~cm}\end{array}$ \\
\hline 4 & Wood & $\begin{array}{l}\text { The length }: 13,4 \mathrm{~cm} \\
\text { The width }: 13,5 \mathrm{~cm}\end{array}$ \\
\hline 5 & Glass & $\begin{array}{l}\text { The length }: 13,3 \mathrm{~cm} \\
\text { The width }: 13,3 \mathrm{~cm}\end{array}$ \\
\hline 6 & Aluminium & $\begin{array}{l}\text { The length }: 13,4 \mathrm{~cm} \\
\text { The width }: 13,4 \mathrm{~cm}\end{array}$ \\
\hline
\end{tabular}

As for the shape of the media barrier is shown in Figure 6 . The influence of testing technique of barrier by blocking tag shown in Figure 7.

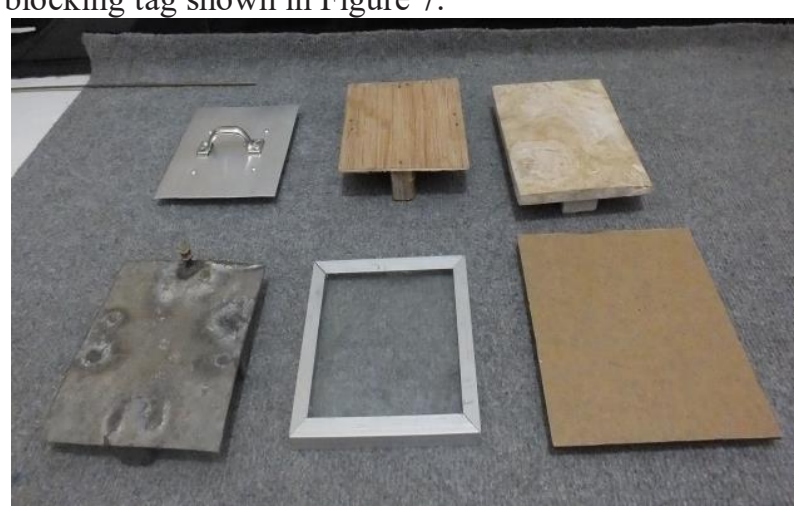

Fig. 6. Shape of Material barriers to testing. 


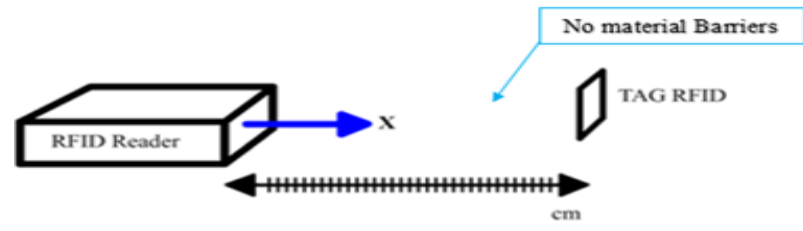

(a)

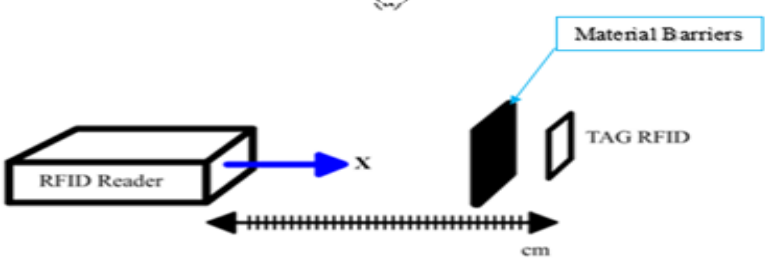

(b)

Fig. 7. Testing techniques for blocking tags with media barrier (a) Testing without the media barrier (b) testing with media barrier.

\subsubsection{The tag is inserted into the media barrier}

On testing the tag is inserted into the media barrier use with barrier thicknesses are shown in Table 3 while regarding the barrier size dimensions shown in Table 4.

Table 3. The thickness of each barrier materials used.

\begin{tabular}{|c|c|c|}
\hline No & Material Barrier & Thickness (mm) \\
\hline 1 & Iron & 0,5 \\
\hline 2 & Marble & 6 \\
\hline 3 & Acrylic & 2 \\
\hline 4 & Wood & 2 \\
\hline 5 & Glass & 5 \\
\hline 6 & Aluminium & 0,5 \\
\hline
\end{tabular}

Table 4. The dimensions of the media barrier used to block tags.

\begin{tabular}{|c|c|l|}
\hline No & Material Barrier & $\begin{array}{l}\text { The Dimensions Of } \\
\text { The Media Barrier }\end{array}$ \\
\hline 1 & Iron & $\begin{array}{l}\text { The length }: 13,4 \mathrm{~cm} \\
\text { The width }: 13,6 \mathrm{~cm} \\
\text { The High }: 17,8 \mathrm{~cm}\end{array}$ \\
\hline 2 & Marble & $\begin{array}{l}\text { The length }: 13,4 \mathrm{~cm} \\
\text { The width }: 13 \mathrm{~cm} \\
\text { The High }: 18,8 \mathrm{~cm}\end{array}$ \\
\hline 3 & Acrylic & $\begin{array}{l}\text { The length }: 15,9 \mathrm{~cm} \\
\text { The width }: 13,3 \mathrm{~cm} \\
\text { The High }: 18,2 \mathrm{~cm}\end{array}$ \\
\hline 5 & Wood & $\begin{array}{l}\text { The length }: 13,4 \mathrm{~cm} \\
\text { The width }: 13,5 \mathrm{~cm} \\
\text { The High }: 17,8 \mathrm{~cm}\end{array}$ \\
\hline 6 & Glass & $\begin{array}{l}\text { The length }: 13,3 \mathrm{~cm} \\
\text { The width }: 13,3 \mathrm{~cm} \\
\text { The High }: 18,3 \mathrm{~cm}\end{array}$ \\
\hline
\end{tabular}

Shape of Material barriers that would do this test shown in Figure 8.

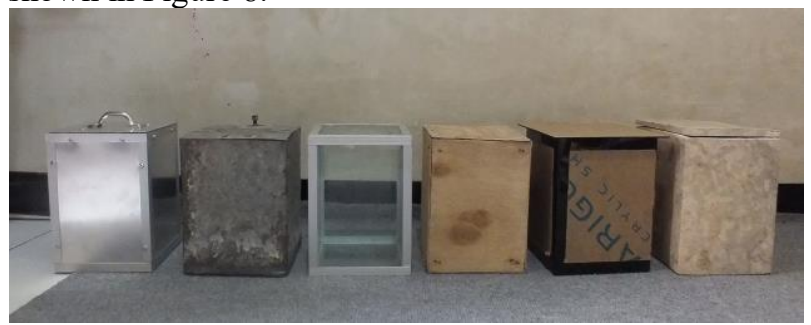

Fig. 8. Shape of material barriers.

As for the influence of testing technique of barrier with the tag is inserted into the media barrier is shown in Figure 9.

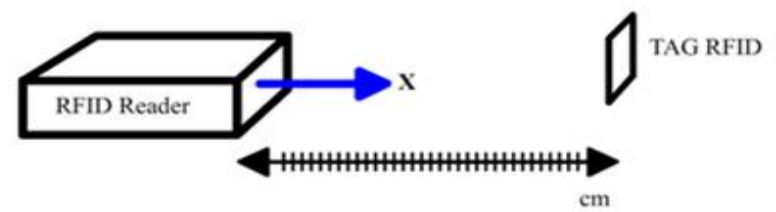

(a)

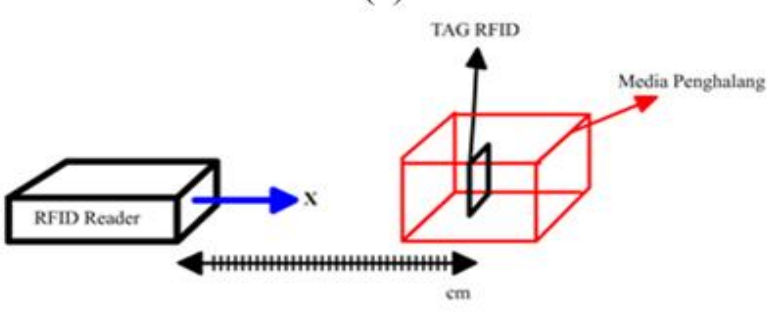

(b)

Fig. 9. Testing techniques for the tag is inserted into the media barrier (a) Testing without the media barrier (b) Testing the tag is inserted into the media barrier.

\subsection{The influence of the position of the tag}

This test is done to find out the influence of the position of the RFID TAGS against the reading of RFID Reader. As for the technique of testing to find out the influence of the position of the tags shown in Figure 10.

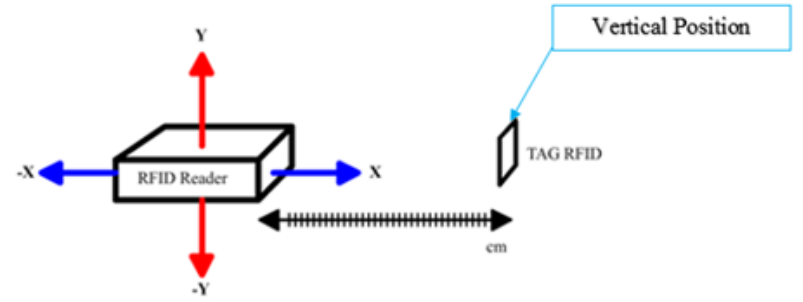

(a)

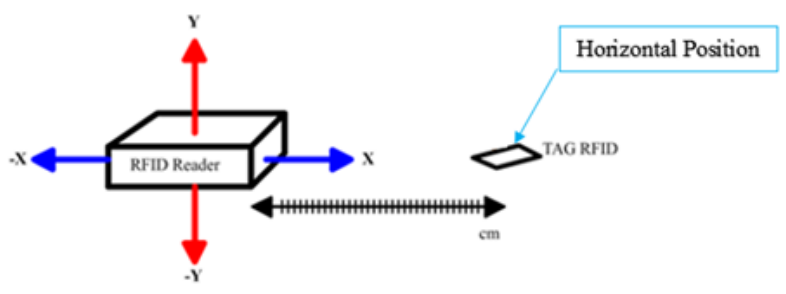

(b)

Fig. 10. Testing technique of positioning tag (a) tag Position Upright (Vertical) Position (b) tag tilted (Horizontal). 


\subsection{Radiation pattern shape}

This testing is done to find out the radiation pattern from the active and passive RFID to be tested. As for the radiation pattern shape testing techniques shown in Figure 11.

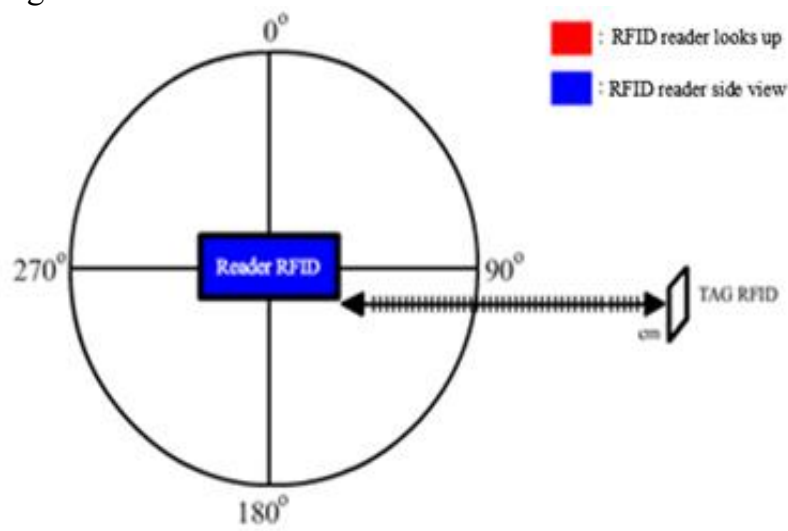

(a)

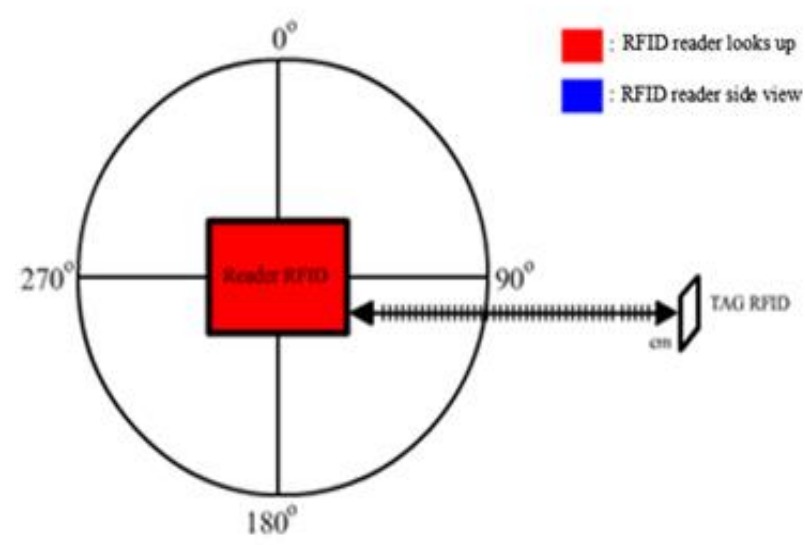

(b)

Fig. 11. The technique of testing of RFID antenna radiation pattern shape (a) Testing radiation pattern horizontally (b) testing of radiation pattern vertically.

\section{Result and discussion}

The results of any testing that is done can be outlined as follows:

\subsection{The influence of the barrier}

On testing the influence of the barrier against a range of active and passive RFID. This is done in two ways: with blocking tag and put the tag on a material barrier. The results of this testing namely:

\subsubsection{The influence of the position of the tag}

Results from testing precludes the tag to find out the influence range of active and passive RFID shown in table 5 and table 6 .
Table 5. The average results of testing active RFID Tag.

\begin{tabular}{|c|c|c|c|c|c|c|c|}
\hline \multirow[b]{2}{*}{ No } & \multicolumn{7}{|c|}{ The Influence Of The Barrier (m) } \\
\hline & $\bar{\Xi}$ & 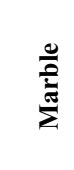 & 参 & 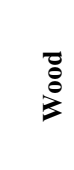 & 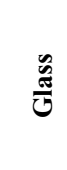 & 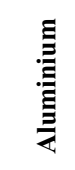 & 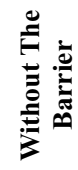 \\
\hline 1 & 2,94 & 5,97 & 10,07 & 10,21 & 8,81 & 2,38 & 11,7 \\
\hline
\end{tabular}

Table 6. The average results of testing a passive RFID tag.

\begin{tabular}{|c|c|c|c|c|c|c|c|}
\hline \multirow[b]{2}{*}{ No } & \multicolumn{7}{|c|}{ The Influence Of The Barrier (cm) } \\
\hline & 泀 & 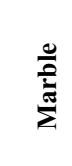 & $\frac{.0}{2}$ & $\frac{\ddot{g}}{8}$ & $\begin{array}{l}\tilde{\tilde{\sigma}} \\
\tilde{\tilde{\sigma}}\end{array}$ & 晜 & 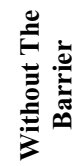 \\
\hline 1 & 16,9 & 42,5 & 42,7 & 41,6 & 40,7 & 0 & 43,0 \\
\hline
\end{tabular}

Based on table 5 shows that aluminium is very giving effect on the range of active RFID and wood very do not give effect on the range active RFID. For passive RFID, on the basis of table 6 shows that aluminium is very giving effect on the range of passive RFID and wood very do not give effect on the range of passive RFID. As for the tag is inserted into the test material barrier is shown in table 7 and table 8.

Table 7. The average results of testing active RFID Tag.

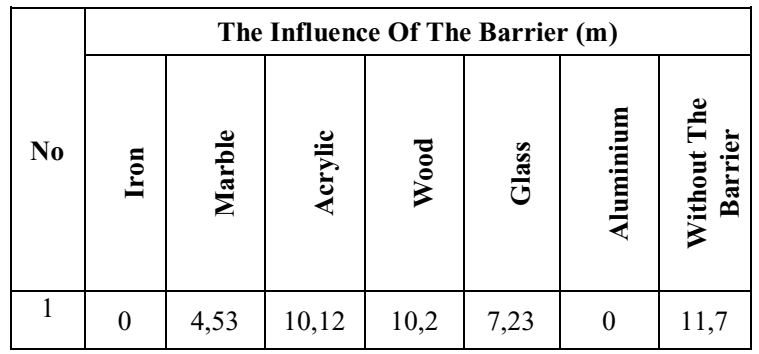

Table 8. The average results of testing a passive RFID tag.

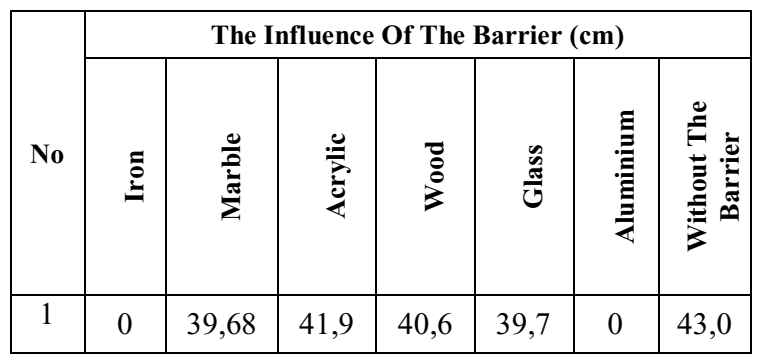

Based on Table 7 shows that aluminium is very giving effect on the range of active RFID and Acrylic very do not give effect on the range active RFID. For passive RFID, on the basis of Table 8 shows that aluminium is very giving effect on the range of passive RFID and Acrylic very do not give effect on the range of passive RFID. 


\subsubsection{The influence of the position of the tag}

Results from testing the influence of the position of the tags shown on Table 9 and Table 10.

Table 9. Average test results influence of the position of the tag against the range of active RFID.

\begin{tabular}{|c|c|c|c|c|c|c|c|c|}
\hline \multirow{3}{*}{ No } & \multicolumn{9}{|c|}{ Upright Position } & \multicolumn{5}{|c|}{ Oblique Position } \\
\cline { 2 - 9 } & \multicolumn{9}{|c|}{ Measuring Direction (m) } \\
\cline { 2 - 9 } & $\mathrm{Y}$ & $-\mathrm{Y}$ & $\mathrm{X}$ & $-\mathrm{X}$ & $\mathrm{Y}$ & $-\mathrm{Y}$ & $\mathrm{X}$ & $-\mathrm{X}$ \\
\hline 1 & 1,9 & 1,9 & 11,7 & 11,5 & 1,2 & 2,9 & 3,5 & 5,9 \\
\hline
\end{tabular}

Based on table 9 shows that in an upright position on the best active RFID range found at position " $\mathrm{X}$ " i.e. $11.7 \mathrm{~m}$, whilst the tilted position on the best active RFID range found at position "-X" i.e. $5.9 \mathrm{~m}$.

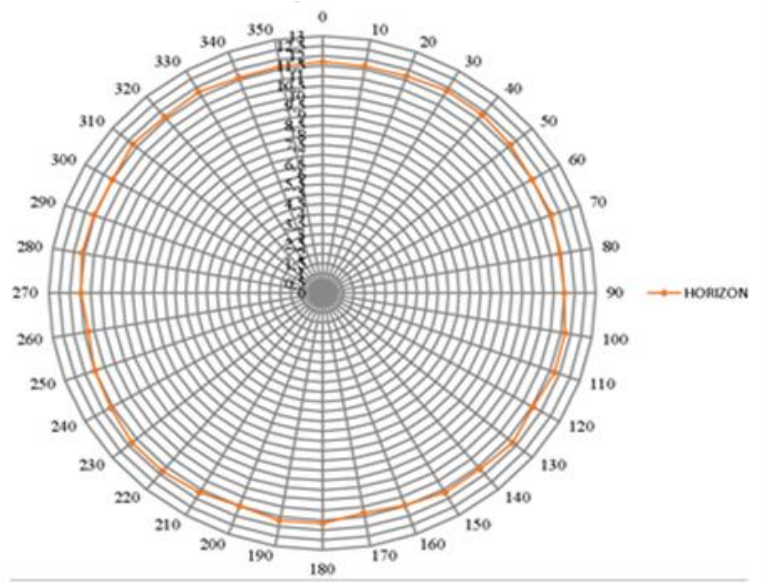

(a)
Tabel 10. Average test results influence of the position of the tag against the range of passive RFID.

\begin{tabular}{|c|c|c|c|c|c|c|c|}
\hline \multicolumn{7}{|c|}{ Upright Position } & \multicolumn{4}{|c|}{ Oblique Position } \\
\hline \multicolumn{7}{|c|}{ Measuring Direction (cm) } \\
\hline $\mathrm{Y}$ & $-\mathrm{Y}$ & $\mathrm{X}$ & $-\mathrm{X}$ & $\mathrm{Y}$ & $-\mathrm{Y}$ & $\mathrm{X}$ & $-\mathrm{X}$ \\
\hline 07,22 & 108,04 & 43,02 & 42,92 & 70,26 & 72,8 & 93,94 & 94,18 \\
\hline
\end{tabular}

Based on Table 10 shows that in an upright position on the best passive RFID range found at position "-Y" i.e. $108.4 \mathrm{~cm}$, whilst the tilted position on the best passive RFID range found at position "-X" i.e. $94.18 \mathrm{~cm}$.

\subsubsection{Radiation Pattern Shape}

Results from testing a form of radiation pattern between active and passive RFID shown in Figure 12 and Figure 13.

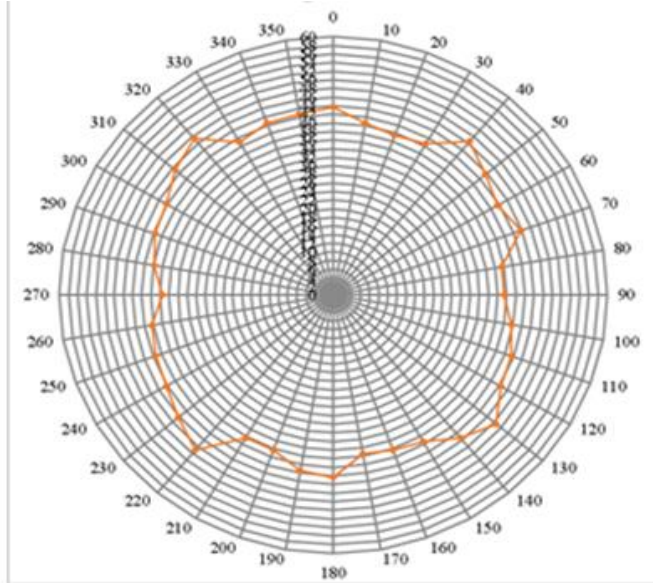

(b)

Fig. 12. The shape of the radiation pattern from the active and passive RFID horizontally.

In Figure 12(a) shows the results of a shape of active RFID radiation pattern horizontally and Figure 12(b) shows the results of a form of passive RFID radiation pattern horizontally. Radiation pattern of active RFID form the shape of a circle. This was the influence of the use of antenna monopole used by active RFID so on active RFID mempropagasikan can signal to the

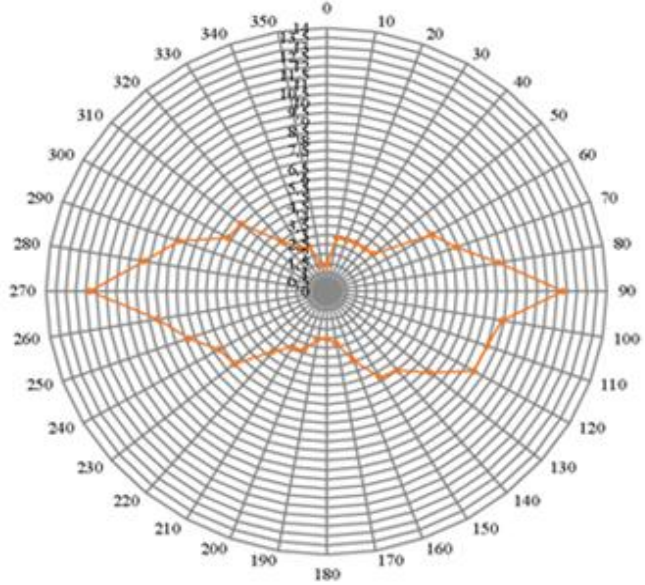

(a) direction of the ruling or commonly called are omnidirectional. While the use of passive RFID on coil used as an antenna radiation pattern shaping such Images 12(b). RFID passive radiation pattern shaping like a box, this means that there is some corner of a passive RFID is that propagasinya decreases and there are some corners of this passive RFID propagasinya ride.

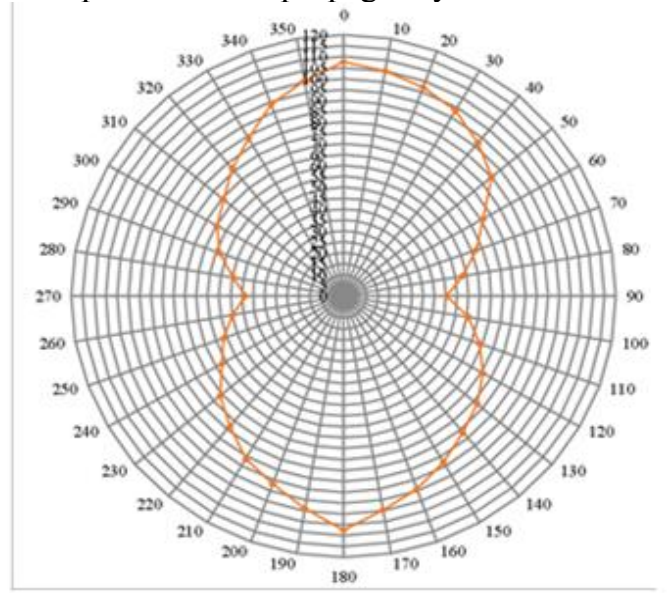

(b)

Fig. 13. The shape of the radiation pattern from the active and passive RFID vertically 
On active RFID antenna using the monopole is obtained that the form radiasinya patterns as in figure 13(b) which shows the propagation of the most distant signal coverage obtained at an angle of 90 degrees and 270 degrees, while in passive RFID obtained that form the pattern of radiasinya is shown as shown in Figure 13(b) indicating that the reach of the most distant signals obtained at an angle of 0 degrees and 180 degrees.

\section{Conclusion}

The results of this research is on testing the influence of media barrier with the tag only hindered obtained that between media of different influence barrier against the range of passive RFID and active RFID.

On active RFID, aluminum gives the most influence on the range of reading RFID Reader I.e. average value of done is $2.38 \mathrm{~m}$. whereas the lowest Wood give influence on the range of reading RFID active i.e. average value of done was $10.21 \mathrm{~m}$. On passive RFID, aluminum gives the most influence on the range of passive RFID reading, which is the average value of done was $0 \mathrm{~cm}$. acrylic while least give influence on the range of the RFID reading, which is the average value of done is $42.7 \mathrm{~cm} .2$ ) On active RFID or RFID passive can be inferred that the laying position tags give influence on the range of readings on the position of the direction of $Y, X-Y$, and-X.

On active RFID antenna using monopole has the shape of a circular radiasinya/pattern exudes all direction or ominidirectional while in passive RFID which use coils of copper as the antenna radiation pattern has the form as box or does it mean also emits all directions but there are some specific angle they have decreased their signal propagation.

\section{References}

1. M. Latief, Sistem Identifikasi Menggunakan Radio Frequency Identification (RFID), Saintek, vol. 5, no. 1, (2016)

2. M. Kaur, M. Sandhu, N. Mohan, and P. S. Sandhu, RFID Technology Principles, Advantages, Limitations \&amp; Its Applications, Int. J. Comput. Electr. Eng., vol. 3, no. 1, pp. 1793-8163, (2011)

3. E. Ilie-Zudor, Z. Kemény, P. Egri, and L. Monostori, The Rfid Technology and Its Current Applications, Isbn, vol. 963, pp. 86586-5, (2006)

4. K. Finkenzeller, RFID HANDBOOK: Fundamentals and Applications in contactless Smart Card, Radio Frequency Identification and Near-Field Communication, Third Edit. (A John Wiley and Sons, Ltd., Publication, 2010)

5. P. V. Nikitin and K. V. S. Rao, Effect of Gen2 protocol parameters on RFID tag performance, 2009 IEEE Int. Conf. RFID, RFID 2009, pp. 117122, (2009)

6. D. Semiconductor, Application Note 83 Fundamentals of RS - 232 Serial Communications,
Signals, pp. 1-9, (2008).

7. Northern Computer Inc, Wiegand Interface Definition, no. January, p. 7050, (1996).

Corresponding author: mochammad.junus@polinema.ac.id 